\title{
The impact of maintenance on peri-implant health
}

\section{Cassiano Kuchenbecker RÖSING(a) Tiago FIORINI(a) \\ Alex Nogueira HAAS(a) \\ Franciso Wilker Mustafa Gomes \\ MUNIZ(b)}

Rui Vicente OPPERMANN(a)

Cristiano SUSIN(c)

(a) Universidade Federal do Rio Grande do Sul - UFRS, School of Dentistry, Department of Conservative Dentistry, Porto Alegre, RS, Brazil.

(b) Universidade Federal de Pelotas - UFPel, Department of Periodontology, Pelotas, RS, Brazil.

(c) University of North Carolina, School of Dentistry, Department of Periodontology, Chapel Hill, NC, USA.

Declaration of Interests: The authors certify that they have no commercial or associative interest that represents a conflict of interest in connection with the manuscript.

Corresponding Author:

Cassiano Kuchenbecker Rösing

E-mail: ckrosing@hotmail.com

htrps://doi.org/10.1590/1807-3107bor-2019.vol33.0074

Submitted: June 10, 2019

Accepted for publication: June 13, 2019

Last revision: June 18, 2019
Abstract: Most of the literature evaluating dental implants focuses on implant survival, which is a limited proxy for the successful rehabilitation of patients with missing teeth. Success should include not only survival but also lack of mechanical, biological, and esthetics problems. A comprehensive review of local and systemic risk factors prior to implant placement will allow the tailoring of treatment planning and maintenance protocols to the patient's profile in order to achieve longitudinal success of the therapy. This review discusses the role of controlling different risk factors and prevention/treatment of peri-implant mucositis in order to avoid peri-implantitis. Although the literature addressing the topic is still scarce, the existing evidence shows that performing optimal plaque control and regular visits to the dentist seem to be adequate to prevent peri-implant lesions. Due to impossibility of defining a probing depth associate with peri-implant health, radiographic evaluations may be considered in the daily practice. So far, there is a strong evidence linking a past history of periodontal disease to peri-implant lesions, but this is not so evident for other factors including smoking and diabetes. The prevention of biological complications starts even before implant placement and include a broader analysis of the patient risk profile and tailoring the rehabilitation and maintenance protocols accordingly. It should be highlighted that the installation of implants does not modify the patient profile, since it does not modify genetics, microbiology or behavioral habits of any individual.

Keywords: Peri-Implantitis; Maintenance; Dental Implants.

\section{Introduction}

Since the discovery of osseointegration by professor Per-Ingvar Branemark in the middle 1960's, several surgical, prosthetic, and technological developments have dramatically changed implant dentistry. Recently, lower implant therapy costs have popularized the rehabilitation of fully and partially edentulous patients with the direct implication that an increasing number of individuals at greater risk of mechanical and biological failures/complications receive implants. Some of these failures can be observed in shorter periods of time, but most take place after years of function. 
The recently published World Workshop on the Classification of Periodontal and Peri-implant diseases and conditions defined a peri-implant healthy mucosa as a core of connective tissue covered by epithelium with underlining tissues that harbor the osseointegration. Clinically, the absence of signs of clinical inflammation is necessary for concluding that a peri-implant site is healthy. Peri-implant diseases are broadly divided into peri-implant mucositis and peri-implantitis depending on whether bone loss has occurred. ${ }^{1}$ Whereas peri-implant mucositis is ubiquitous, peri-implantitis seem to affect approximately $20 \%$ of patients who have received implants. ${ }^{2,3}$ Importantly, peri-implantitis seem to present a nonlinear pattern of progression, which accelerates after approximately a decade. ${ }^{4,5}$ The true prevalence/incidence of peri-implant diseases are mostly unknown since only few studies follow rehabilitated patients for longer periods of time. In this context, the concepts of survival and success are frequently misunderstood and used interchangeably. Whereas a surviving implant affected by peri-implantitis will only be lost at the final stages of the disease, this could not be considered success, which includes absence of any kind of aesthetic, biological or mechanical failures/complications.

Periodontal and peri-implant diseases appear to have enough similarities to warrant a parallel between gingivitis and peri-implant mucositis, as well as between periodontitis and peri-implantitis. ${ }^{6,7}$ Oral biofilms cause gingivitis and peri-implant mucositis and they share several clinical and histological features; however, bleeding on probing is more frequent around implants compared to teeth. Compared to periodontitis, lesions around implants are twice as large, exhibit a more destructive inflammatory profile, and likely a faster progression. ${ }^{8}$ Clinically, probing depths are deeper and the probe tends to reach the alveolar crest more easily around implants than teeth. Biofilm control has been shown to be effective around teeth and implants with the caveat that root surfaces are easier to access than implant surfaces due to intricacies in macro-design and surface roughness. ${ }^{9}$

Long-term studies supporting the importance of periodontal maintenance are available in the literature. Collectively, they demonstrate that even patients with extremely advanced periodontitis or those at higher risk of disease can be successfully

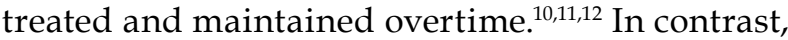
limited data on the long-term maintenance of dental implants is available. In this review, the literature regarding peri-implant maintenance was scrutinized and summarized aiming at providing clinicians and researchers a broad overview of the current evidence.

\section{Evidence for peri-implant maintenance}

Main characteristics of the systematic reviews published in the last 10 years addressing the impact of maintenance/supportive care on the peri-implant tissues.

Table 1 shows the main characteristics of systematic reviews published in the last 10 years have investigated the benefits of peri-implant maintenance to achieve and maintain peri-implant health overtime. . $^{3,13,14,15,16}$ Some of these reviews have addressed specific topics of maintenance (i.e., influence of type of retainment in overdentures or influence of abutment material/design on peri-implant tissues), while others aimed estimating prevalence/incidence of biological complications and also evaluated the impact of maintenance therapy on these complications, although the supportive care itself was not the main focus of the investigation. ${ }^{15,17,18}$ On the other hand, one review addressed the impact of maintenance/supportive care as main outcome and one the survival and success rate of implants treated of peri-implantitis. ${ }^{16}$ In order to evaluate the quality of these systematic reviews, the "Assessment of Multiple Systematic Reviews - 2" tool were used. ${ }^{19}$ Amstar has been specifically developed as a comprehensive critical appraisal instrument, originally only for randomized controlled trials. Amstar 2 is a 16 item tool that include also non-randomized trials, remaining simple and straightforward to use. Reviews can be classified as high, moderate, low or critically low quality according to specific criteria.

Monje et al. ${ }^{15}$ published a systematic review with 13 longitudinal studies investigating the effects of maintenance therapy on the occurrence of peri-implant 
Table 1. Main characteristics of the systematic reviews published in the last 10 years addressing the impact of maintenance/ supportive care on the peri-implant tissues.

\begin{tabular}{|c|c|c|c|c|}
\hline Author, year, & $\begin{array}{l}\text { Number and Design } \\
\text { of studies included / } \\
\text { Meta-analysis }\end{array}$ & Main outcome & $\begin{array}{l}\text { AMSTAR } \\
2 \text { rate }\end{array}$ & Main Findings \\
\hline $\begin{array}{l}\text { Dreyer et al., } \\
2018^{3}\end{array}$ & $\begin{array}{l}\text { Fifty-seven studies } \\
\text { were included in the } \\
\text { systematic review / } \\
\text { Meta-Analysis performed }\end{array}$ & $\begin{array}{l}\text { Evaluate the prevalence, } \\
\text { incidence and risk factors of } \\
\text { peri-implantitis in general } \\
\text { population }\end{array}$ & High & $\begin{array}{l}\text { Median prevalence of peri-implantitis was } \\
9.0 \% \text { (SSA } 10.9 \% \text { ) for regular participants of } \\
\text { a prophylaxis program, } 18.8 \% \text { (SSA } 8.8 \% \text { ) for } \\
\text { patients without regular preventive maintenance }\end{array}$ \\
\hline $\begin{array}{l}\text { Atieh et al., } \\
2013^{13}\end{array}$ & $\begin{array}{l}9 \text { (cross-sectional, } \\
\text { prospective and } \\
\text { retrospective), } \\
\text { Meta-Analysis performed }\end{array}$ & $\begin{array}{l}\text { Frequency of peri-implant } \\
\text { diseases in general } \\
\text { and high-risk (history of } \\
\text { periodontal disease, smoking, } \\
\text { and diabetes) patients }\end{array}$ & Moderate & $\begin{array}{l}\text { Patients receiving supportive care } \\
\text { presented reduced overall frequency of } \\
\text { peri-implantitis (14.3\% - } 95 \% \mathrm{Cl} 11.8 \% \text { to } \\
\text { 16.9\%;) compared to general population } \\
\text { (18.8\% - } 95 \% \mathrm{Cl} 16.8 \% \text { to } 20.8 \%)\end{array}$ \\
\hline $\begin{array}{l}\text { Zangrano et al., } \\
2015^{14}\end{array}$ & $\begin{array}{l}5 \text { prospective and } 5 \\
\text { retrospective studies } \\
\text { were included / } \\
\text { Meta-Analysis not } \\
\text { performed }\end{array}$ & $\begin{array}{l}\text { Implant survival and } \\
\text { peri-implant bone loss in } \\
\text { periodontitis patients treated } \\
\text { of periodontal disease }\end{array}$ & Moderate & $\begin{array}{l}\text { Among patients with periodontitis submitted to } \\
\text { treatment, those who complied with periodontal } \\
\text { maintenance presented mean peri-implant } \\
\text { bone loss of } 0.32-0.77 \mathrm{~mm} \text {, compared } \\
\text { to } 2.50-2.19 \mathrm{~mm} \text { for those who were not } \\
\text { compliant (based on one study) } \\
\text { Among patients with periodontitis submitted to } \\
\text { treatment, those who complied with periodontal } \\
\text { maintenance presented similar periodontal and } \\
\text { peri-implant conditions than healthy patients } \\
\text { (based on } 2 \text { studies) }\end{array}$ \\
\hline $\begin{array}{l}\text { Monje et al., } \\
2016^{15}\end{array}$ & $\begin{array}{l}13 \text { clinical trials (design } \\
\text { description not clear) } \\
\text { / Meta-Analysis not } \\
\text { performed }\end{array}$ & $\begin{array}{c}\text { Impact of maintenance } \\
\text { therapy/supportive care on } \\
\text { the incidence of peri-implant } \\
\text { diseases }\end{array}$ & Moderate & $\begin{array}{l}\text { Pacients without PIMT presented more mucositis } \\
\text { and peri-implantitis incidence, both at implant and } \\
\text { individual level. } \\
\text { PIMT might be } 5 \text { to } 6 \text { mo because of the positive } \\
\text { significant impact on incidence of peri-implantitis }\end{array}$ \\
\hline $\begin{array}{l}\text { Rocuzzo et al., } \\
2018^{16}\end{array}$ & $\begin{array}{l}12 \text { Non- } \mathrm{RCT} \\
\text { (prospective and } \\
\text { retrospective); } 1 \mathrm{RCT} \text {, } \\
\text { Meta-Analysis performed }\end{array}$ & $\begin{array}{l}\text { Implant survival, success } \\
\text { and recurrence of disease } \\
\text { in patients treated for } \\
\text { peri-implantitis who afterward } \\
\text { received supportive care }\end{array}$ & High & $\begin{array}{c}\text { Survival rates after } 7 \text { years reached approximately } \\
70 \%(69.63 \%-98.72 \% \text { - two studies). } \\
\text { Success and recurrence of disease presented } \\
\text { heterogenous results }\end{array}$ \\
\hline
\end{tabular}

RCT: randomized clinical trials; PIMT: Peri-implant maintenance.

diseases. The major finding was that the frequency of peri-implant maintenance had strong effect on the incidence of peri-implant diseases. Applying meta-analytic approaches, the authors estimated a $25 \%$ reduction on the incidence of peri-implantitis for patients under maintenance care compared to those not receiving maintenance. Moreover, it was suggested that the reasonable interval for periimplant maintenance should be between 5 to 6 months. The review also confirmed the association between history of periodontitis and occurrence of peri-implantitis. More recently, Rocuzzo et al. ${ }^{16}$ studied clinical outcomes (implant survival, success and recurrence of disease) in a sample of individuals with implants treated for peri-implantitis and that afterward received supportive care for at least 3 years. Authors included 13 articles for quantitative appraisal.
Although the studies included in the review did not present a control group without supportive care, and most of them did not provide a detailed description of the protocol (including recall frequency and procedures executed), authors observed that biofilm control (both daily home care and professionally) are effective in avoid recurrence of disease and yield a survival rate of between approximately $70 \%$ to $98 \%$ after seven years (based on two studies).

In regards to compliance, smokers and patients with previous history of periodontitis presented higher chances of being non-compliant. ${ }^{20}$ Another study evaluating factors related to compliance with peri-implant maintenance also showed that history of periodontitis was associated with lower compliance. ${ }^{21}$ However, most importantly, it was demonstrated that treated periodontitis patients presented better 


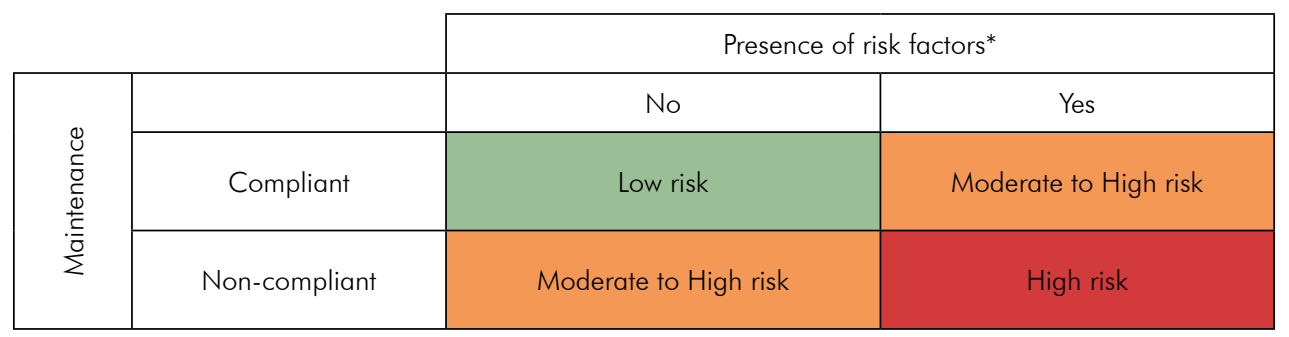

*Previous history of periodontitis (strong evidence), smoking (moderate evidence), diabetes (limited evidence)

Figure 1. Proposed model of risk for peri-implantitis according to maintenance status and history of periodontal disease.

compliance. Collectively, patient education and periodontal treatment seem to improve compliance and long-term results.

Figure 1 presents a proposed scheme for maintenance regimen taking into consideration the patient's exposure to different risk or prognostic factors. For instance, patients with history of periodontitis, poor supragingival plaque control, smokers, and diabetics who are at higher risk for peri-implantitis should have a stricter maintenance protocol. Unfortunately, limited is known about the specific effect of these factors on the outcomes of peri-implant maintenance, which means that this model will evolve as evidence becomes available.

An evidence approach refers to the use of the best available evidence to the treatment of individual cases. ${ }^{22}$ Figure 2 illustrates a case of success peri-implant maintenance over 3 years after loading of implants, taking into consideration the evidence discussed here. The patient is a 55 yearsold male, with no history of periodontitis, never smoked, and had good oral hygiene. The patient was rehabilitated with five implants in the maxilla with screwed retained crowns. A maintenance program comprising of peri-implant/periodontal assessments, professional biofilm control, and oral hygiene instructions was established with a 6-months interval. Probing depth, peri-implant attachment loss and bleeding on probing were recorded on all implants and teeth. Over the 3 years of follow-up, no clinical signs of inflammation or bone loss were detected, clearly indicating health of the peri-implant tissues.

On the other hand, Figure 3 presents the opposite scenario for a 63 years-old female who sought urgent care at the dental school due to spontaneous pain. The patient reported no periodontal maintenance for four year following a full-arch fixed rehabilitation in the mandible. Large amounts of oral biofilm can be seen around the implants and prothesis, and the peri-implant mucosa show signs of inflammation and peri-implant attachment loss. A large ulcerated mucosal lesion on the left side is also evident.

\section{The role of prevention on mucositis}

Prevention of biological and mechanical complications starts even before implant placement, during the diagnosis and treatment planning phases. Besides taking into consideration the local and systemic factors previously mentioned, other factors that should be considered include bone quality and quantity, parafunctional habits, occlusal factors, functional demands, and others. Tailoring the rehabilitation to the patient profile is essential to avoid complications overtime. The same rationale can be applied to the maintenance protocol. It is crucial that patients receive information regarding risks for peri-implant diseases and the importance of maintenance care. For patients considered of moderate to high risk, rehabilitation should be considered, whenever possible, preferring segmented screw retained prosthesis, reduced cantilevers, straight tissue level abutments with implant supra-structures avoiding niches for biofilm accumulation.

While there is strong evidence linking some risk factors such as history of periodontal disease to peri-implantitis, this is not so evident for others including smoking and diabetes. ${ }^{1}$ The absence of direct evidence should not be interpreted as the 

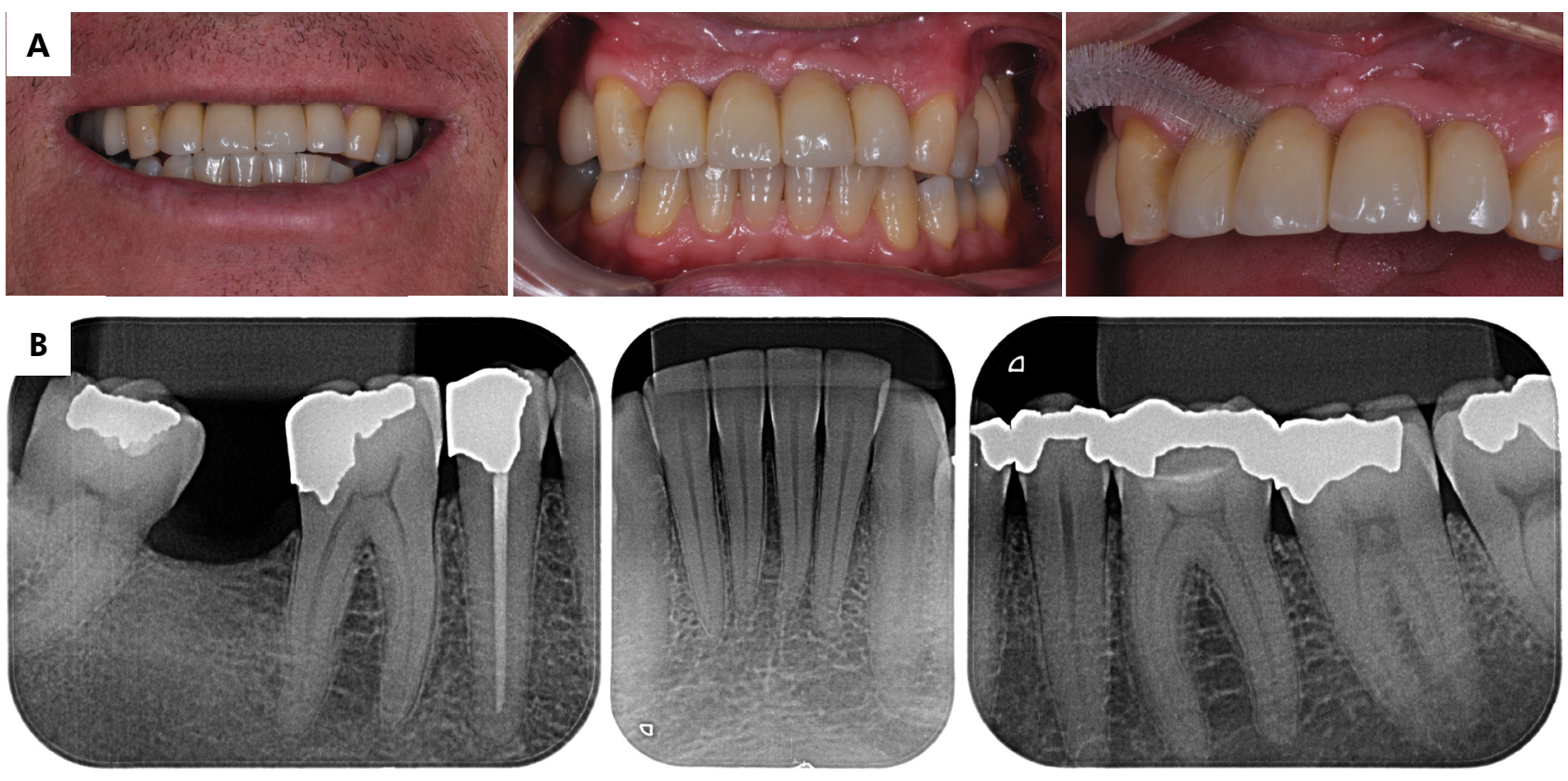

C

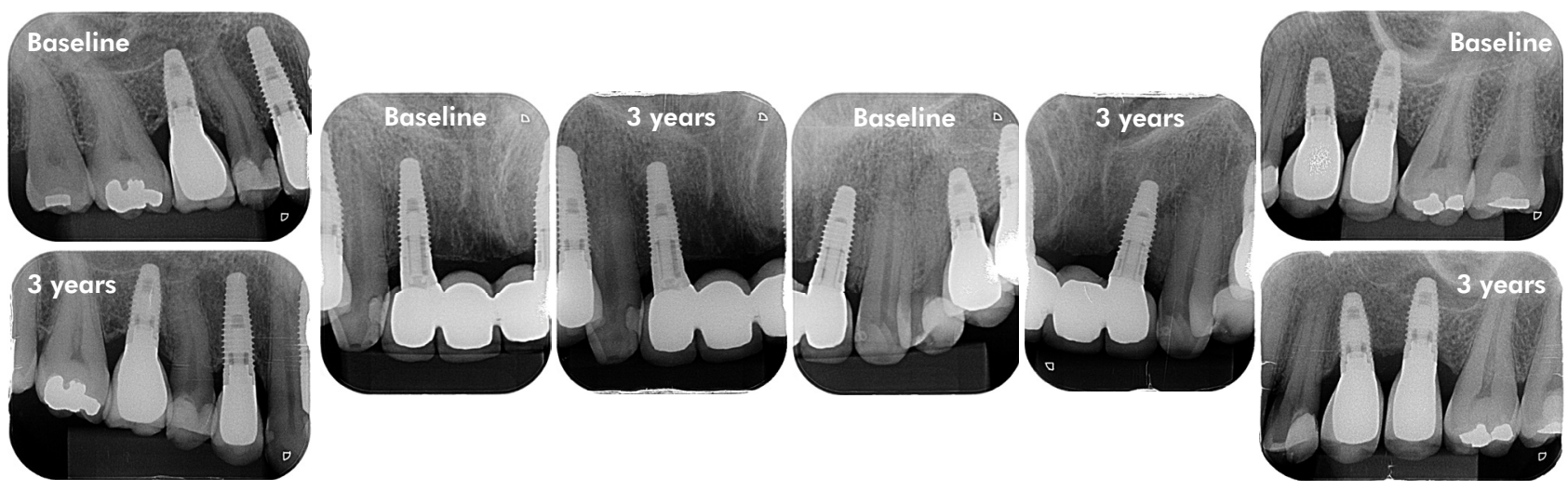

Figure 2. (A) Clinical pictures of a patient receiving peri-implant maintenance for 3 years. (B) Radiographic images of the lower remaining teeth showing no/limited marginal bone loss indicating a negative history of periodontitis. (C) Radiographic images showing no/limited marginal bone levels around dental implants following prosthetic rehabilitation and after 3 years.

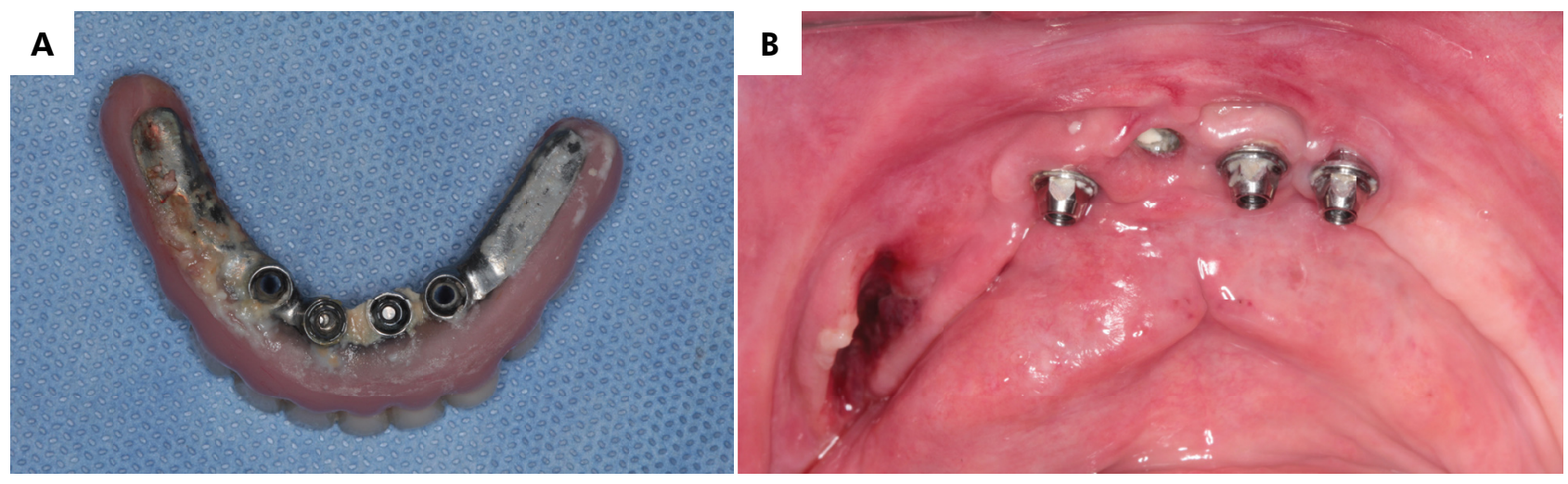

Figure 3. (A) Clinical pictures of a patient who did not receive any peri-implant maintenance 4 years after a lower full-arch fixed rehabilitation. (B) Clinical pictures of implants presenting mechanical and biological complications. A large ulcerated mucosal lesion was observed on the left side. 
evidence of lack of effect, since few studies follow up the patients for enough time and most are based on convenience samples. Therefore, patient risk profile should be considered as a whole and for a broader analysis factors such as smoking and diabetes should not be neglected.

Currently, crucial measures to achieve long term success with implant therapy include oral hygiene instruction and professional mechanical plaque removal. One study with 80 partially edentulous individuals rehabilitated with implants, which were followed for 5 years, demonstrated the importance of maintenance care to prevent peri-implant mucositis to progress to peri-implantitis. ${ }^{23}$ In such study, all patients presented mucositis at baseline and were divided in two groups: one group receiving maintenance care (at least five appointments in the follow-up) and the control group was not under maintenance care, without any dental visits during the study period. Compared to individuals who were enrolled in the preventive protocol, those in the group without maintenance were more prone to develop periimplantitis (43.9\% versus $18 \%$ ), which was defined as the presence of $\mathrm{PD} \geq 5 \mathrm{~mm}$ associated with bleeding on peri-implant probing and/or suppuration with peri-implant bone loss. The authors observed that peri-implantitis lesions do not seem to be system or surface-dependent, but rather associated with worst plaque control in both groups. In addition, studies have shown that good plaque control is associated with peri-implant health and that peri-implant mucositis can be successfully treated by control of biofilm. ${ }^{24,25}$ Altogether, these observations reinforce the importance of individualized preventing programs and constant monitoring in order to long term stability of peri-implant tissues.

\section{Evaluation of existing maintenance}

\section{protocols}

Although the literature shows that the incidence of peri-implant diseases is decreased in patients under constant maintenance therapy, to date, there is no evidence, from randomized clinical trials, which proposed protocol is more adequate to maintain peri-implant tissues healthy. ${ }^{10,12}$ Most of these protocols are conceived based on expert opinions or on the results from studies performed in natural teeth. ${ }^{26}$ It seems reasonable that the assessment should begin with updating the medical and dental histories of the patient. Several clinical examinations are important to be collected, such as condition of the soft tissue, plaque index, calculus, clinical probing depth (PD), presence of bleeding on probing and suppuration, mobility, occlusion and, if clinically indicated, radiographic evaluation may be necessary.

It is known that the incidence of peri-implant diseases can be minimized with routine dental biofilm control. In this sense, the existing maintenance protocols for dental implants are based on home-based cleansing and professional disinfection. Therefore, brushing and interproximal cleansing are essential and, in some cases, single-tufted toothbrushes and chemical agents in dentifrices and/or mouthrinses may be interesting. In the literature, the antiplaque and antigingivitis/mucositis effect of manual toothbrushes were compared to powered and sonic toothbrushes. ${ }^{27}$ This systematic review showed no significant difference to both dental plaque and gingival/mucosal inflammation outcomes between the different toothbrushes. For this reason, when choosing the most appropriated oral hygiene device for individuals with dental implants, the patient preference must be considered.

Table 2 summarizes the most important studies to date on the topic. Most of the maintenance protocols demonstrated in the literature perform oral hygiene instructions and professional calculus and dental biofilm removal in every follow-up visit. The efficacy of this protocol is demonstrated in the literature. ${ }^{28}$ During a mean follow-up period of 18.3 months, the incidence of peri-implant mucositis was less than $10 \%$. In this study, at all follow-up visits, all patients received oral hygiene instructions and professional removal of biofilm from implant necks and prosthesis surfaces, using manual Teflon curettes and powered brushes, respectively. Interproximal cleansing was also indicated. Longitudinally, when individuals were diagnosed with peri-implant mucositis or peri-implantitis, they were treated with $0.2 \%$ 


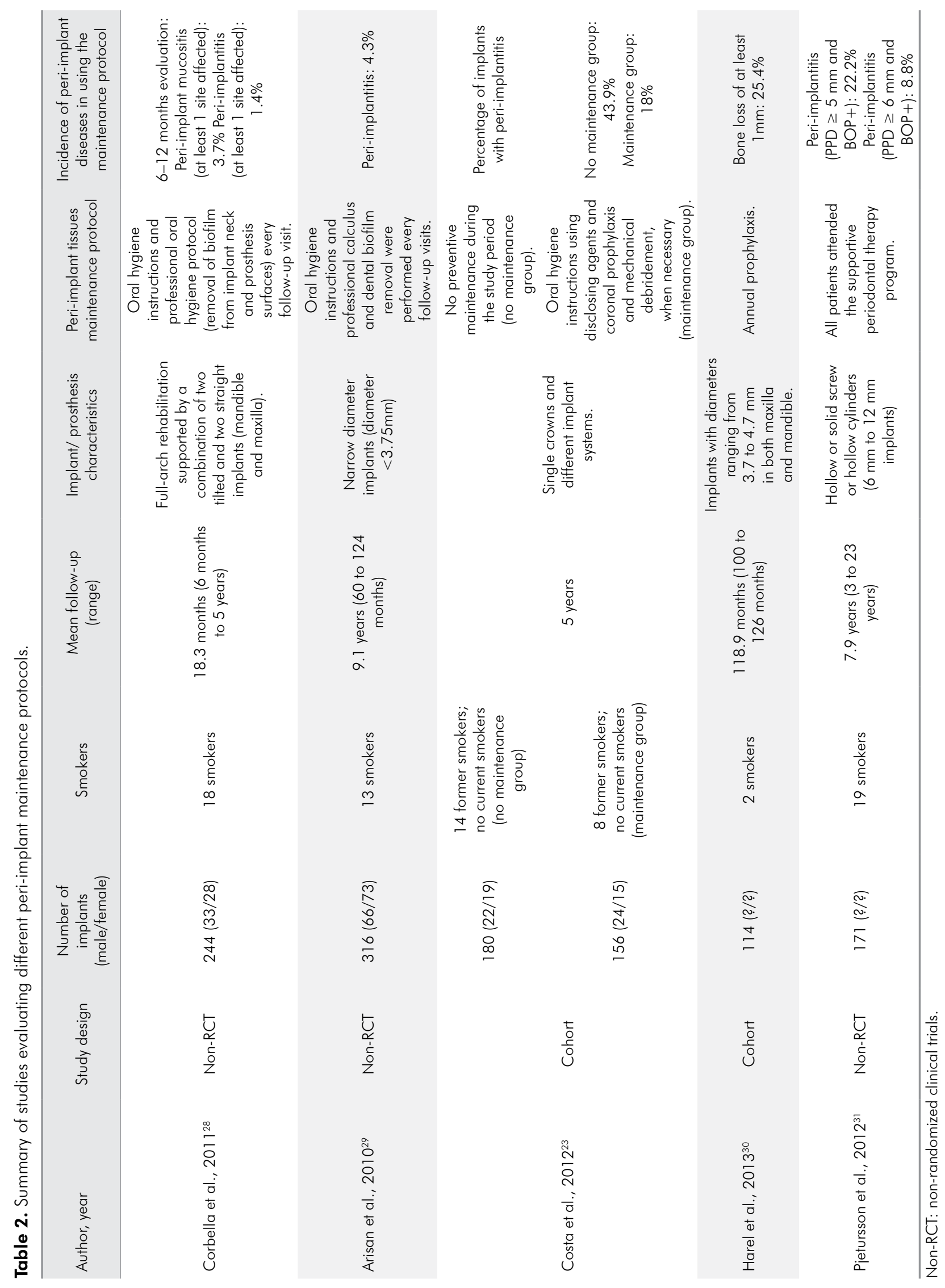


chlorhexidine mouthwash twice a day for 10 days or with $1 \%$ locally delivered chlorhexidine followed by surgical treatment, respectively.

In vitro studies demonstrated that stainless steel scalers increased significantly the implant surfaces roughness, ${ }^{32,33,34}$ which would contraindicate the use of these instruments at the moment. However, one clinical study compared the impact of different composition of scaler materials on polished titanium implant abutment surfaces and demonstrated that the control of biofilm was not significantly different after several scaler materials were used. ${ }^{35}$ For this reason, there is little evidence to suggest that plaque formation is increased on this roughened surface. In this sense, to date, it is important that the implant is routinely cleaned both by the patient and the professional with the best available means.

In the long term, the use of chemical control of biofilm may be unnecessary to prevent peri-implant diseases. One study that involved only patients with clinical signs of peri-implant mucositis showed that chlorhexidine mouthwashes, when used in conjunction with mechanical debridement, provided no additional benefits in comparison to mechanical debridement only. ${ }^{36,37}$

Based on the parameters collected at the follow-up visits, the literature proposed the following protocol: Cumulative Interceptive Supportive Therapy (CIST) ${ }^{25}$ This protocol includes four treatment modalities for different peri-implant tissue conditions, such as mechanical debridement, antiseptic treatment, antibiotic treatment, and regenerative or resective surgery. Although this is a very interesting protocol, to date, no study evaluated the effect to this therapy in the incidence of peri-implant diseases. The CIST protocol is presented as follows:

a. Pocket depth (PD) $<3 \mathrm{~mm}$, no plaque or bleeding on probing: no therapy;

b. $\mathrm{PD}<3 \mathrm{~mm}$ with plaque and/or bleeding on probing: mechanically cleaning, polishing, oral hygienic instructions;

c. PD 4-5 $\mathrm{mm}$ without radiographic bone loss: mechanically cleaning, polishing, oral hygienic instructions plus local anti-infective therapy (e.g. chlorhexidine) for 3 to 4 weeks; d. $\mathrm{PD}>5 \mathrm{~mm}$ with $<2 \mathrm{~mm}$ radiographic bone loss: mechanically cleaning, polishing, microbiological test, local and systemic anti-infective therapy;

e. $\mathrm{PD}>5 \mathrm{~mm}$ with $>2 \mathrm{~mm}$ radiographic bone loss: resective or regenerative surgery.

The use of this protocol supposes that probing depth ranges from 2 to $4 \mathrm{~mm}$ under peri-implant healthy tissue conditions. However, it should be noted that probing depth around implants may be related to implant position. Factors that may influence probing depth includes but are not restricted to implant position related to the bone crest (epi or subcrestally), width of peri-implant tissues and type of implant/abutment connection. In some cases, higher probing depth may not imply peri-implant diseases. For this reason, it is very important to establish the baseline bone level when the prosthesis is installed.

\section{Final remarks}

Herein we reviewed the literature that addresses the role of maintenance/supportive care on the longevity and success of dental implants. In summary, patients should receive individualized, regular supportive care in order to maintain peri-implant health. Management of systemic and local risk factors, including biofilm control, smoking, diabetes, and peri-implant inflammation are paramount to prevent peri-implantitis and peri-implant mucositis. Besides these factors, previous history of periodontitis and complexity of the rehabilitation should be taken into consideration to establish the maintenance protocol and its frequency.

Deviations from health should be always considered, especially due to the fact that periimplant diseases are linked to an inflammatory status that is not considered normal and might represent a systemic inflammatory burden with possible at distance effects. Although the establishment of peri-implant and periodontal maintenance has demonstrated to reduce the occurrence of peri-implant diseases, biological complications may still occur over time. At the moment, there is no clear peri-implant maintenance protocol established in the literature to be applied by clinicians in daily 
practice. However, maintenance/supportive care taking into consideration the measures described in the present article will certainly benefit patients' health. Importantly, replacing compromised teeth with dental implants does not guarantee a long-term functional dentition since the underlying genetics, microbiology, functional demands, and behavioral habits associated with oral diseases are not necessarily changed with the placement of dental implants.

\section{References}

1. Berglundh T, Armitage G, Araujo MG, Avila-Ortiz G, Blanco J, Camargo PM, et al. Peri-implant diseases and conditions: Consensus report of workgroup 4 of the 2017 World Workshop on the Classification of Periodontal and Peri-Implant Diseases and Conditions. J Periodontol. 2018 Jun;89 Suppl 1:S313-8. https://doi.org/10.1002/JPER.17-0739

2. Lee CT, Huang YW, Zhu L, Weltman R. Prevalences of peri-implantitis and peri-implant mucositis: systematic review and meta-analysis. J Dent. 2017 Jul;62:1-12. https://doi.org/10.1016/i.jdent.2017.04.011

3. Dreyer H, Grischke J, Tiede C, Eberhard J, Schweitzer A, Toikkanen SE, et al. Epidemiology and risk factors of peri-implantitis: A systematic review. J Periodontal Res. 2018 Oct;53(5):657-81. https://doi.org/10.1111/ire.12562

4. Derks J, Tomasi C. Peri-implant health and disease. A systematic review of current epidemiology. J Clin Periodontol. 2015 Apr;42 Suppl 16:S158-71. https://doi.org/10.1111/icpe.12334

5. Derks J, Schaller D, Håkansson J, Wennström JL, Tomasi C, Berglundh T. Peri-implantitis - onset and pattern of progression. J Clin Periodontol. 2016 Apr;43(4):383-8. https://doi.org/10.1111/icpe.12535

6. Lang NP, Bosshardt DD, Lulic M. Do mucositis lesions around implants differ from gingivitis lesions around teeth? J Clin Periodontol. 2011 Mar;38 Suppl 11:182-7. https://doi.org/10.1111/j.1600-051X.2010.01667.x

7. Berglundh T, Zitzmann NU, Donati M. Are peri-implantitis lesions different from periodontitis lesions? J Clin Periodontol. 2011 Mar;38 Suppl 11:188-202. https://doi.org/10.1111/j.1600-051X.2010.01672.x

8. Salvi GE, Cosgarea R, Sculean A. Prevalence and mechanisms of peri-implant diseases. J Dent Res. 2017 Jan;96(1):31-7. https://doi.org/10.1177/0022034516667484

9. Gomes SC, Corvello P, Romagna R, Müller LH, Angst PD, Oppermann RV. How do peri-implant mucositis and gingivitis respond to supragingival biofilm control - an intra-individual longitudinal cohort study. Eur J Oral Implantol. 2015;8(1):65-73.

10. Lindhe J, Nyman S. Long-term maintenance of patients treated for advanced periodontal disease. J Clin Periodontol. 1984 Sep;11(8):504-14. https://doi.org/10.1111/j.1600-051X.1984.tb00902.x

11. Rosling B, Serino G, Hellström MK, Socransky SS, Lindhe J. Longitudinal periodontal tissue alterations during supportive therapy. Findings from subjects with normal and high susceptibility to periodontal disease. J Clin Periodontol. 2001 Mar;28(3):241-9. https://doi.org/10.1034/j.1600-051x.2001.028003241.x

12. Axelsson P, Nyström B, Lindhe J. The long-term effect of a plaque control program on tooth mortality, caries and periodontal disease in adults. Results after 30 years of maintenance. J Clin Periodontol. 2004 Sep;31(9):749-57. https://doi.org/10.1111/i.1600-051X.2004.00563.x

13. Atieh MA, Alsabeeha NH, Faggion CM Jr, Duncan WJ. The frequency of peri-implant diseases: a systematic review and meta-analysis. J Periodontol. 2013 Nov;84(11):1586-98. https://doi.org/10.1902/jop.2012.120592.

14. Zangrando MS, Damante CA, Sant'Ana AC, Rubo de Rezende ML, Greghi SL, Chambrone L. Long-term evaluation of periodontal parameters and implant outcomes in periodontally compromised patients: a systematic review. J Periodontol. 2015 Feb;86(2):201-21. https://doi.org/10.1902/jop.2014.140390.

15. Monje A, Aranda L, Diaz KT, Alarcón MA, Bagramian RA, Wang HL, et al. Impact of maintenance therapy for the prevention of peri-implant diseases: a systematic review and meta-analysis. J Dent Res. 2016 Apr;95(4):372-9. https://doi.org/10.1177/0022034515622432

16. Roccuzzo M, Layton DM, Roccuzzo A, Heitz-Mayfield LJ. Clinical outcomes of peri-implantitis treatment and supportive care: A systematic review. Clin Oral Implants Res. 2018 Oct;29 Suppl 16:331-50. https://doi.org/10.1111/clr.13287

17. Hultin M, Komiyama A, Klinge B. Supportive therapy and the longevity of dental implants: a systematic review of the literature. Clin Oral Implants Res. 2007 Jun;18 Suppl 3:50-62. https://doi.org/10.1111/j.1600-0501.2007.01447.x

18. Salvi GE, Zitzmann NU. The effects of anti-infective preventive measures on the occurrence of biologic implant complications and implant loss: a systematic review. Int J Oral Maxillofac Implants. 2014;29 Suppl:292-307. https://doi.org/10.11607/jomi.2014suppl.g5.1 
19. Jung JH, Dahm P. Reaching for the stars: rating the quality of systematic reviews with the Assessment of Multiple Systematic Reviews (AMSTAR) 2. BJU Int. 2018 Nov; 122(5):717-8. https://doi.org/10.1111/bju.14571

20. Monje A, Wang HL, Nart J. Association of preventive maintenance therapy compliance and peri-implant diseases: a cross-sectional study. J Periodontol. 2017 Oct;88(10):1030-41. https://doi.org/10.1902/jop.2017.170135

21. Hu KF, Lin YC, Ho KY, Chou YH. Compliance with supportive periodontal treatment in patients with dental implants. Int J Oral Maxillofac Implants. 2017 Nov/Dec;32(6):1364-70. https://doi.org/10.11607/jomi.5457

22. Kazdin AE. Evidence-based treatment and practice: new opportunities to bridge clinical research and practice, enhance the knowledge base, and improve patient care. Am Psychol. 2008 Apr;63(3):146-59. https://doi.org/10.1037/0003-066X.63.3.146

23. Costa FO, Takenaka-Martinez S, Cota LO, Ferreira SD, Silva GL, Costa JE. Peri-implant disease in subjects with and without preventive maintenance: a 5-year follow-up. J Clin Periodontol. 2012 Feb;39(2):173-81. https://doi.org/10.1111/j.1600-051X.2011.01819.x

24. Zitzmann NU, Berglundh T, Marinello CP, Lindhe J. Experimental peri-implant mucositis in man. J Clin Periodontol. 2001 Jun;28(6):517-23. https://doi.org/10.1034/j.1600-051x.2001.028006517.x

25. Lang NP, Berglundh T, Heitz-Mayfield LJ, Pjetursson BE, Salvi GE, Sanz M. Consensus statements and recommended clinical procedures regarding implant survival and complications. Int J Oral Maxillofac Implants. 2004;19 Suppl:150-4.

26. Lyle DM. Implant maintenance: is there an ideal approach? Compend Contin Educ Dent. 2013 May;34(5):386-90.

27. Esposito M, Worthington HV, Thomsen $P$, Coulthard P. Interventions for replacing missing teeth: maintaining health around dental implants. Cochrane Database Syst Rev. 2004;(3):CD003069. https://doi.org/10.1002/14651858.CD003069.pub2

28. Corbella S, Del Fabbro M, Taschieri S, De Siena F, Francetti L. Clinical evaluation of an implant maintenance protocol for the prevention of peri-implant diseases in patients treated with immediately loaded full-arch rehabilitations. Int J Dent Hyg. 2011 Aug;9(3):216-22. https://doi.org/10.1111/j.1601-5037.2010.00489.x

29. Arisan V, Bölükbaşi N, Ersanli S, Ozdemir T. Evaluation of 316 narrow diameter implants followed for 5-10 years: a clinical and radiographic retrospective study. Clin Oral Implants Res. 2010 Mar;21(3):296-307. https://doi.org/10.1111/j.1600-0501.2009.01840.x

30. Harel N, Moses $O$, Palti A, Ormianer Z. Long-term results of implants immediately placed into extraction sockets grafted with $\beta$-tricalcium phosphate: a retrospective study. J Oral Maxillofac Surg. 2013 Feb;71(2):e63-8. https://doi.org/10.1016/i.joms.2012.09.022

31. Pjetursson BE, Helbling C, Weber HP, Matuliene G, Salvi GE, Brägger U, et al. Peri-implantitis susceptibility as it relates to periodontal therapy and supportive care. Clin Oral Implants Res. 2012 Jul;23(7):888-94. https://doi.org/10.1111/j.1600-0501.2012.02474.x

32. Fox SC, Moriarty JD, Kusy RP. The effects of scaling a titanium implant surface with metal and plastic instruments: an in vitro study. J Periodontol. 1990 Aug;61(8):485-90. https://doi.org/10.1902/jop.1990.61.8.485

33. Matarasso S, Quaremba G, Coraggio F, Vaia E, Cafiero C, Lang NP. Maintenance of implants: an in vitro study of titanium implant surface modifications subsequent to the application of different prophylaxis procedures. Clin Oral Implants Res. 1996 Mar;7(1):64-72. https://doi.org/10.1034/j.1600-0501.1996.070108.x

34. Meschenmoser A, d'Hoedt B, Meyle J, Elssner G, Korn D, Hämmerle H, et al. Effects of various hygiene procedures on the surface characteristics of titanium abutments. J Periodontol. 1996 Mar;67(3):229-35. https://doi.org/10.1902/jop.1996.67.3.229

35. Hasturk H, Nguyen DH, Sherzai H, Song X, Soukos N, Bidlack FB, et al. Comparison of the impact of scaler material composition on polished titanium implant abutment surfaces. J Dent Hyg. 2013 Aug;87(4):200-11.

36. Porras R, Anderson GB, Caffesse R, Narendran S, Trejo PM. Clinical response to 2 different therapeutic regimens to treat peri-implant mucositis. J Periodontol. 2002 Oct;73(10):1118-25. https://doi.org/10.1902/jop.2002.73.10.1118

37. Thöne-Mühling M, Swierkot K, Nonnenmacher C, Mutters R, Flores-de-Jacoby L, Mengel R. Comparison of two full-mouth approaches in the treatment of peri-implant mucositis: a pilot study. Clin Oral Implants Res. 2010 May;21(5):504-12.

https://doi.org/10.1111/j.1600-0501.2009.01861.x 